\title{
NMR spectroscopy of HIV-1 gp120 outer domain
}

\author{
M Sastry $^{1 *}, L X u^{1}$, S Bhattacharya ${ }^{2}$, GJ Nabel $^{1}$, CA Bewley ${ }^{3}$, PD Kwong ${ }^{1}$ \\ From AIDS Vaccine 2012 \\ Boston, MA, USA. 9-12 September 2012
}

\section{Background}

The outer domain (OD) of HIV-1 gp120 has been proposed as a minimal immunogen to elicit broadly neutralizing antibodies. However, OD is heavily glycosylated, contains many flexible regions, and immunization with a number of different OD variants has thus far failed to elicit neutralizing antibodies. An understanding of the conformational space sampled by the OD in its unliganded state, however, may assist in the use of OD as an immunogen.

\section{Methods}

We developed a method to isotopically enrich glycoproteins using a mammalian expression system that exploits the high level of protein expression obtained from an adenoviral vector, and employed heteronuclear NMR spectroscopy to obtain structural and dynamic information of unliganded OD. Multidimensional NMR experiments were recorded on uniformly labeled ${ }^{15 \mathrm{~N} / 13} \mathrm{C}$ OD as well as on samples selectively enriched in ${ }^{15} \mathrm{~N}$-labeled Gly, Ile, Leu and Val. Experiments for backbone assignments were also recorded on an OD sample enriched in ${ }^{15 \mathrm{~N} / 13} \mathrm{C}$ for Ile, Leu and Val.

\section{Results}

We successfully produced isotopically labeled OD samples, suitable for NMR analysis. We also identified Gly, Ser, Val, Leu and Ile residues using samples selectively enriched in ${ }^{15} \mathrm{~N}$ for Gly, Val, Leu and Ile. Standard triple resonance NMR experiments on the isotopically labeled OD were combined with backbone experiments recorded on a second sample - that was selectively enriched in ${ }^{15 \mathrm{~N} / 13} \mathrm{C}$ for Ile, Leu and Val - to assign HN, C', $\mathrm{C}_{\mathrm{alpha}}$ and $\mathrm{N}$ backbone resonances in about 80 of the 220 residues of OD.

\section{Conclusion}

We succeeded in assigning $\sim 1 / 3$ of the backbone for unliganded OD with triple resonance experiments. Extension of these assignments with NOESY experiments is now proceeding. Our results indicate that a solution structure of the highly glycosylated HIV-1 gp120 OD is feasible.

\section{Author details}

${ }^{1}$ Vaccine Research Center, NIAID/NIH, Bethesda, MD, USA. ${ }^{2}$ New York Structural Biology Center, New York, NY, USA. ${ }^{3}$ NIDDK, National Institutes of Health, Bethesda, MD, USA.

Published: 13 September 2012

doi:10.1186/1742-4690-9-S2-P20

Cite this article as: Sastry et al:: NMR spectroscopy of HIV-1 gp120 outer domain. Retrovirology 2012 9(Suppl 2):P20.

\section{Submit your next manuscript to BioMed Central and take full advantage of: \\ - Convenient online submission \\ - Thorough peer review \\ - No space constraints or color figure charges \\ - Immediate publication on acceptance \\ - Inclusion in PubMed, CAS, Scopus and Google Scholar \\ - Research which is freely available for redistribution

